\title{
Implementing Nature-Based Solutions: the role of experts in co-creation processes and new governance models
}

\author{
Oscar AZZIMONTI, University of Milan Bicocca, Italy \\ Federico AILI, ISOCARP Institute, The Netherlands
}

\begin{abstract}
The environmental crisis of the XXI century is increasingly manifesting its negative impacts, especially in cities. Air pollution, heat island effects, adverse events such as flooding are only some of the most recurrent issues affecting public health and quality of life in cities. At the same time, the challenges but also the opportunities related to urbanization have encouraged a global effort to re-think urban environments in an innovative way, especially through new solutions that address multiple issues and wide societal challenges (environmental, social, economic) at the same time. In this context, the concept of nature-based solutions (NBS) is receiving more and more attention, with various research studies and applications in several cities. Particularly in Europe, the European Commission is funding various projects and initiatives, becoming a global leader in innovating with nature to achieve more sustainable and resilient societies. NBS projects are often associated with the concept of ecosystem services and they are usually considered more complex and uncertain than traditional grey infrastructure projects. In fact, NBS are essentially dynamic (natural features evolve over time), they present a character of multiplicity (in terms of stakeholders involved, design solutions considered and co-benefits provided), and they are adaptive (tailored to the conditions of the local context without a one-fits-all solutions). These intrinsic features raise relevant issues and demand more flexible governance models and participatory processes as inclusive as possible. The complexity of nature-based solutions is also reflected in the multiple barriers to implementation, not only financial; these usually include the lack of adequate knowledge and experience, difficulties in capturing the multiple benefits of NBS, possible trade-offs and conflicts between the groups involved. Experts can support both local authorities and local communities along the process, thus playing an important role in the successful implementation of projects. Our contribution focuses on the inclusion of expert knowledge in the design, implementation and monitoring of NBS. Drawing from the latest European projects and reports and literature, the paper will underline some of the main challenges and criticalities related to the involvement of experts in green policy-making. More specifically, the paper briefly illustrates some macro-themes that deserve attention, in particular the tensions between local and expert knowledge in the participative co-creation of NBS and the political legitimacy of expert knowledge; and the local capacities to cope with NBS implementation, monitoring, maintenance and management in the medium-long term.
\end{abstract}

\section{Keywords}

Nature-based Solutions, experts, participation, governance, local communities, co-creation Keyword 


\section{Introduction}

The increasing gravity of the environmental crisis of the XXI century requires innovative ways of rethinking urban environments, with solutions able to address wide societal challenges and multiple issues at the same time. Nature-Based Solutions represent an emerging and promising field due to the simultaneous co-benefits they can provide. Thus, it is not surprising to notice a proliferation of funding programmes, and several international organisations, agencies and institutions specializing on this topic.

The aim of the paper is to investigate the role of international experts in the implementation of NBS projects. In several cases, teams of international experts are appointed to implement NBS projects tailored to the conditions of the local context. The dynamics and the tensions between international expertise and local communities do not seem to receive particular attention in the discourse of Nature-Based Solutions. From a methodological point of view, the paper completes a literature review of project deliverables and open access publications of EU-funded projects, in particular under the Programme Horizon 2020. This choice depends on the fact that Europe is currently playing a leading role in NBS, and H2020 projects represent a precious repository of resources, references and very recent case study.

The paper does not consider all projects funded under the umbrella programme of NBS, but it focuses on those which bring advancement in governance model and stakeholder engagement. In particular, the paper investigates the role of experts in relation to the co-creation activities and the establishment of Living Labs.

The conclusion of the paper is dedicated to the main findings, general reflections, open issues and the space for further research.

\section{Background research}

\subsection{The complexity and the relevance of Nature-Based Solutions}

The environmental crisis of the XXI century is increasingly manifesting its negative impacts, especially in cities. Air pollution, heat island effects, adverse events such as flooding are only some of the most recurrent issues affecting public health and quality of life in cities. Urbanisation in general brings many opportunities but also critical challenges related to sustainable development, environmental quality and social justice. The acknowledgment of these wide societal challenges (environmental, social, economic) and the need for effective actions have encouraged a global effort to re-think urban environments in a more innovative and sustainable way, especially through new solutions that address multiple issues at the same time.

In this context, the concept of Nature-Based Solutions (NBS) is receiving more and more attention, with various research studies and applications in several cities. Particularly in Europe, the European Commission has been funding various projects and initiatives, becoming a global leader in innovating with nature to achieve more sustainable and resilient societies. In this regard, the EU has financed more than 20 projects on NBS with the Horizon 2020 programme between 2014 and 2021, facilitating the production of several project deliverables, reports, policy briefs, recommendation, lessons learned, business cases, etc. The leading role of the European Union is also confirmed by the most accepted definition of Nature-Based Solutions, which is provided by the European Commission in the EU Research and Innovation policy agenda. NBS are considered "solutions that are inspired and supported by nature, which 
are cost-effective, simultaneously provide environmental, social and economic benefits and help build resilience. Such solutions bring more, and more diverse, nature and natural features and processes into cities, landscapes and seascapes, through locally adapted, resource-efficient and systemic interventions" (European Commission 2021, p.6).

Starting from this definition, but including also other definitions of NBS (for instance the one provided by IUCN, the International Union for Conservation of Nature), the debate around Nature-based Solutions seems to consistently emphasize some specific features. First of all, NBS are usually considered more multifaceted and uncertain than traditional grey infrastructure, and they are closely associated with the concept of ecosystem services. Secondly, NBS are essentially dynamic (natural features evolve over time), and they present a character of multiplicity, in terms of design solutions considered, stakeholders involved and co-benefits provided. Thirdly, they are considered inevitably adaptive, tailored to the conditions of the local context without a one-fits-all solution. As a consequence, the implementation of NBS projects raise relevant issues and challenges, demanding more flexible governance models and participatory process as inclusive as possible. Several barriers to implementation (not only financial) are usually recognised. The most common include the lack of adequate knowledge and experience, difficulties in capturing the multiple benefits of NBS, possible trade-offs and conflicts between the groups involved.

As a result, due to their complexity and potentialities, Nature-Based Solutions constitute a new and expanding field of research and practice. In this sense, it is not surprising to see a proliferation of experts and new professional figures assisting both local authorities and local communities along the process of design, implementation and monitoring of NBS. These experts play an important role at various levels and their relation with other actors is worthy to be further explored.

The scope of this research focuses in particular on the Horizon 2020 and the NBS projects funded under this Programme. This choice has been made taking into account various elements. Firstly, $\mathrm{H} 2020$ projects are often considered decentralized and polycentric forms of environmental governance (O'Sullivan et al. 2020), representing an interesting setting to analyze the role of international experts and their relation with local communities. Secondly, despite the large production of project deliverables, handbooks, reports etc., this topic often seems to be taken for granted, or at least it does not receive the same attention as other relevant themes. Last but not least, the Horizon 2020 Programme constitutes an important repository of knowledge, experiences, processes and project results, well documented in various dissemination materials.

\subsection{Experts and expertise in the field of Nature-based Solutions.}

Despite some years of research, various projects and a multitude of case studies, NBS still constitutes an emergent field in European urban policies. The European Union has promoted and coordinated several projects on NBS, introducing the concept and innovative urbanistic ideas for a sustainable urban development in many European cities, with the aim of becoming a world leader in the field (EU Commission, 2020). Elaborating on existing environmental issues, NBS prefigure some desirable targets and set some short- and medium-term interventions.

Following a co-productionist framework (Jasanoff, 2004), it is clear that nature-based solutions are ongoing scientific and political processes, negotiated between diverse actors at multiple scales. As the field is relatively new and the scientific knowledge on the topic is not consolidated, the theoretical definitions and the territorial implementation of the projects influence each other in a continuous and prolific dialogue. Moreover - given the uncertainty of the socio-ecological dynamics, the complexity, and the variety of European urban governance - the processes underpinning NBS and the outcomes depend on context-specific features. Considering the high stakes and the urgency of the issues related to urban climate change and sustainability, NBS may be considered as a post-normal science issue, whereby an 
extended peer-review that include not only different scientific disciplines, but also lay people, contribute to define the problems, the research priorities and questions (Funtowicz and Ravetz, 1993).

This paper focuses on the role of the expert knowledge in framing and implementing nature-based solutions. The position of expert knowledge is often blurred and contested by the stakeholders involved in the projects. In fact, European urban decision-makers have increasingly relied on expert knowledge and on scientific data and facts to elaborate and legitimate their policies in the last decades (Caselli, 2020). As a consequence, a plurality of expert actors has formed. Not only universities, but also research institutes, private think tanks and consulting companies offer their expertise to public decision makers. Their contribution is not just descriptive, but also prescriptive. In this sense, the expertise for policy-making does not correspond to the traditional scientific activities (Pellizzoni, 2011). The expertise is characterised by technical and scientific competences, applied to specific policy issues, and therefore answers to questions that are not scientifically defined. The policy issues are always interdisciplinary and hardly reducible to pre-defined competences and the timing of policy making differ from that of science, requiring fast and clear actions.

Another distinctive feature of the expertise is that of the asymmetrical relationality (Pellizzoni, 2011). The opinions and the advice of the experts are considered, by definition, as more reliable and trustworthy than lay people's. Although the expertise in policy-making differs from the traditional scientific knowledge, it is deemed as a legitimising argumentation. In this sense the experts are in a privileged position in the arena of policy-making, if compared to the other non-expert actors. The expert knowledge is therefore invoked and deployed not only by public policy makers, but also by citizens, grassroot associations, businesses and all the stakeholders involved. Different expertises may therefore collide and become an important part of the political debate. The expert knowledge hence represents a fundamental asset in European projects on NBS and deserves particular attention, as it may be shared and contested between different stakeholders and, accordingly, be at the centre of the political debate.

\section{Methodology}

This paper intends to study the role of expert knowledge in designing and implementing nature-based solutions in the contexts of the EU-funded projects. By reviewing the project reports and other relevant documents, the research analyses the figure of the experts in different contexts and focuses on the main challenges and criticalities emerged in the local development of NBS. As a first step, the research investigates how the stakeholders' roles and positions are determined and, in particular, how the projects recognize the experts and their knowledge, in contrast with lay citizens. Then the research looks at the interactions between different stakeholders and at how the projects design participative activities and the collaboration between different stakeholders.

In particular, this study is framed on three macro-topics:

- Tensions and conflicts between local communities and institutional expert knowledge. The research intends to highlight conflictual moments between different stakeholders and namely the tensions involving the expert knowledge.

- Political legitimacy of scientific expertise: depoliticization and re-politicisation. The study attempts to comprehend whether scientific expertise is used for avoiding conflicts and political debate and whether there are alternative expertise in the field that contribute to re-politicise the issue.

- Local capacity to cope with NBS implementation, monitoring, maintenance and management in the medium-long term. The research focuses on the local knowledge capacity building. 
These issues are defined based on a preliminary analysis and on the authors' experience on EU projects. Stemming from this framework, the research activities are flexible and, depending on the gradual findings, may undertake other directions that do not necessarily correspond to the initial framework. The research is based on an in depth review of EU project reports and documents on NBS. After a first overview of the latest projects on NBS and urban GIs, few of them are selected. The criteria of selection include the reflexive capacity and the availability of reports and documentation on the themes of the paper.

The research acknowledges some limitations in the work. First, the available resources for the literature review are mainly constituted by public deliverables written by partners who are directly involved in the project: some challenges or weaknesses might have been omitted or not emphasised. Second, the projects considered have different timelines and some of these are still ongoing, therefore it is very difficult to capture the project results in the short term. Third, the tools of analysis here deployed do not allow a full comprehension of the issues. An in-depth analysis of one or more case studies with interviews to relevant stakeholders would facilitate a better understanding of the role of the experts. Future research may integrate the general overview presented here with more detailed information on the role of experts and on the stakeholders' perception of it in the projects.

\subsection{EU-funded project considered}

The EU-funded projects under the Programme Horizon 2020 represent a series of interesting case studies to explore the role of experts in the implementation of Nature-Based Solutions. This research has selected and analysed some specific projects under Horizon 2020 in the last years. Project reports and deliverables have been considered for a literature review. The following main criteria for the selection of projects have been used: the presence of pilot cities (in other words the participation of municipalities and public authorities in the project), a specific attention to the involvement of local stakeholders and citizens engagement, and a strong reflection on the topic of local governance. In this sense, projects which included the development of Living Labs (sometimes called in different ways) received a privileged attention, due to the fact that these labs constitute a setting where to test and experiment the interaction between local communities and expertise.

The following projects are considered (the descriptions are taken from the: EU Handbook for practitioners on NBS).

- CLEARING HOUSE: CLEARING HOUSE addresses a global challenge that unites European and Chinese cities in their quest to develop more resilient cities and liveable societies. Our main focus is on tree-based green infrastructure which is the basis for "urban forests as nature-based solutions". Urban Forests as nature-based solutions (UF-NBS) are nature-based solutions that build on tree-based urban ecosystems to address societal challenges, simultaneously providing ecosystem services for human well-being and biodiversity benefits. UF-NBS include peri-urban and urban forests, forested parks, small woods in urban areas, and trees in public and private spaces. CLEARING HOUSE will analyse and develop the potential of UF-NBS- across China and Europe - in order to enhance the resilience of cities facing major ecological, socio-economic, and human wellbeing challenges.

- CLEVER Cities: "CLEVER Cities aims to drive a new kind of nature-based urban transformation for sustainable and socially inclusive cities across Europe, South America and China. Its local teams including citizens, businesses, knowledge partners and local authorities are co-creating nature-based interventions in Hamburg, London and Milan to regenerate cities, improve the environment, generate economic opportunities and make deprived urban districts healthier places to live. Through multi-disciplinary learning, exchange and collaboration with Fellow cities Belgrade, Larissa, Madrid, Malmö, Sfântu Gheorghe and Quito, the project is developing a CLEVER Solutions Basket with innovative technological, business, financing and governance 
solutions to adapt nature-based interventions for the needs of towns and cities around the world" (NBS Handbook, p.107).

- Connecting Nature: "Brings in action to feed the initiation and expansion of economic and social enterprises in production and large-scale implementation of NBS in urban settings to measure the impact of these initiatives on climate change adaptation, health and well-being, social cohesion and sustainable economic development." ((European Commission, 2021: p. 71))

- GREEN SURGE: "GREEN SURGE prepared strategies to design urban green approaches: integrating green and grey approaches, connecting green areas, utilizing the multipurpose character of the green approach and involving citizens in urban planning."((European Commission, 2021: p.30)

- GrowGreen: "The project aims to accelerate the delivery of NBS strategies across Cities. By investing in NBS pilot projects in Manchester, Valencia and Wroclaw that deliver quantified improvements in climate and water resilience, social, environmental and economic performance, the project will develop a robust evidence base and a replicable approach that will enable this acceleration across Europe and the rest of the world. "((European Commission, 2021: p. 73).

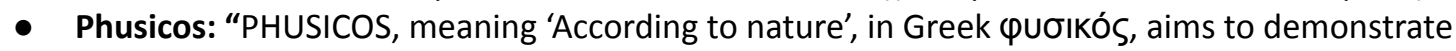
how nature inspired solutions reduce the risk of extreme weather events in rural mountain landscapes. The focus of PHUSICOS is on demonstrating the effectiveness of NBS and their ability to reduce the impacts from hydro-meteorological hazards (flooding, landslide, erosion, drought, snow avalanche) in rural mountain landscapes. The NBS considered and implemented in PHSUICOS are cost-effective and sustainable measures inspired by nature that attenuate, and in some cases prevent, the impacts of natural hazard events and thereby the risks that affect the exposed regions." ((European Commission, 2021: p. 239).

- proGIreg: ProGIreg uses nature for urban regeneration with and for citizens. The project is funded by the European Commission under the Horizon 2020 programme and runs from June 2018 until 2023. In proGIreg's front-runner cities' Living Labs, eight different nature-based solutions (NBS) are harnessed to create productive green infrastructure that not only helps improve living conditions and reduce vulnerability to climate change, but also provides measurable economic benefits to citizens and entrepreneurs in post-industrial urban districts. The follower cities learn from the front runners through mutual exchange and replicate successful approaches. All the work done in the Living Labs is characterized by an inclusive approach, whereby local citizens, governments, businesses, NGOs, and universities co-create the nature-based solutions together, from planning to implementation. To ensure replication beyond the project cities, pGIreg develops self-sustaining business models for nature-based solutions, based on scientific assessment of the multiple benefits they provide for social, health, ecological, and economic regeneration (European Commission, 2021: p. 111).

- UNaLAb: UNaLab is generating evidence of the benefits, cost-effectiveness, economic viability and replicability of NBS targeting climate change mitigation and adaptation, and sustainable water management. UNaLab activities promote smart, inclusive, resilient and sustainable urban communities through stakeholder co-creation of Urban Living Labs (ULLs) and local NBS demonstrations, and co-evaluation of NBS impact. Collaborative knowledge production among the network of UNaLab partner cities yields project results that reflect diverse urban socio-economic realities, along with differences in the size and density of urban populations, local ecosystem characteristics and climate conditions. UNaLab project outcomes that support further replication and up-scaling of NBS include an ULL model, ICT tools for NBS co-creation and co-monitoring, applicable business and financing models, and guidance on governance-related structures and processes to support NBS uptake." (European Commission, 2021: p. 75). 


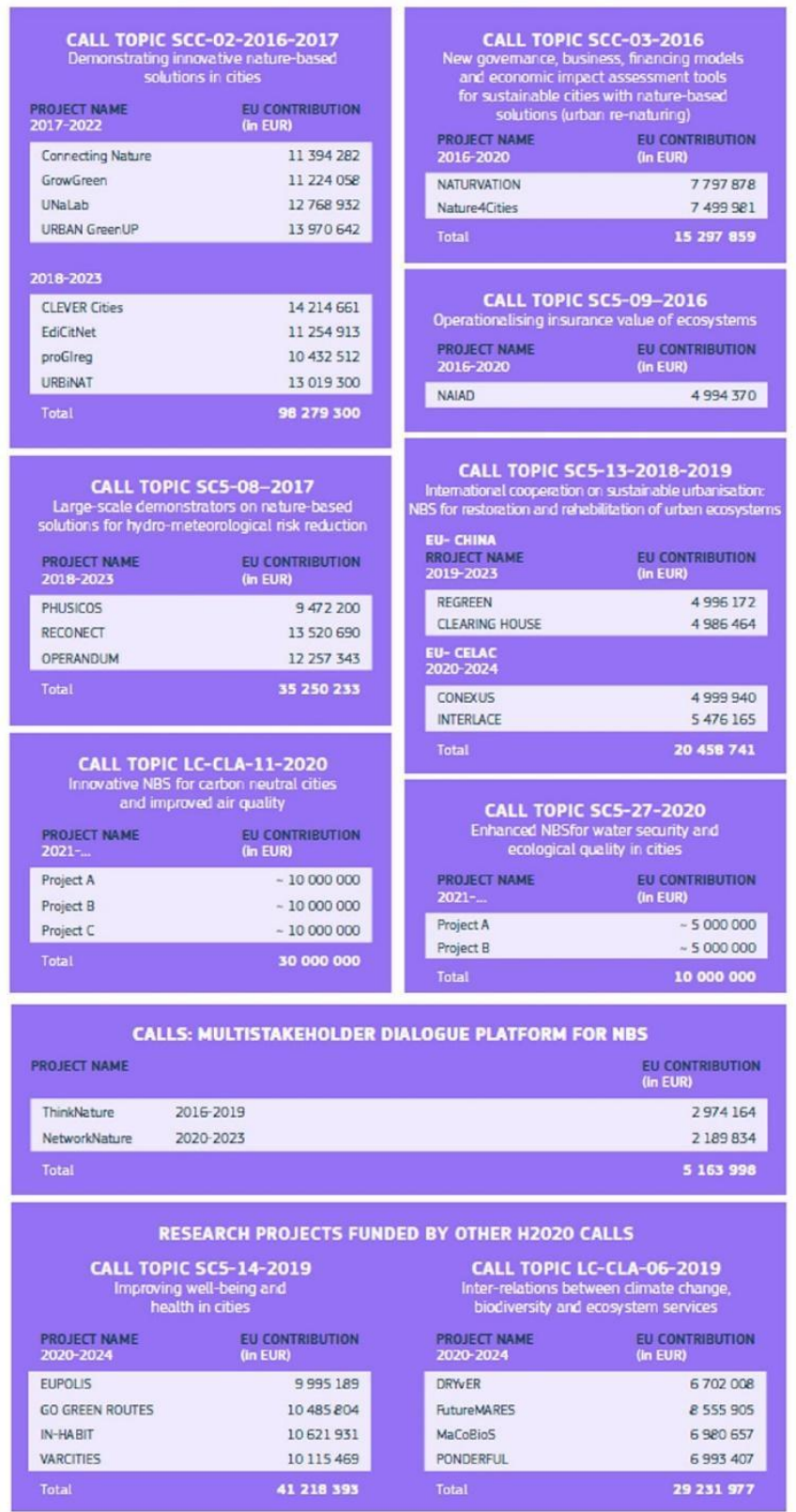

Figure 1. The portfolio of EU projects. Source: European Commission, 2020.

\section{Research results - Review of the EU projects.}

In order to understand and evaluate the role of experts in these projects, some elements have been systematically reviewed in the selected EU-funded projects. These include:

- Stakeholder analysis, with the goal to identify the expertise and its relation with other subjects;

- Governance models and issues about participation, to investigate the participation of local communities on the co-creation of knowledge; 
- The Living Labs and related co-creation activities, in order to study tensions, conflicts and matters of political legitimacy.

\subsection{Stakeholder analysis - Who are the experts?}

A recurring approach in the EU projects we took in consideration is the initial mapping of relevant stakeholders, especially at the local level. Selected partners of the project consortium usually perform this specific task at the early stage of the project, with the declared intention of involving them from the early stage of the project. In most of the cases, the framework for reference is the quadruple helix approach, where four categories are identified: Academia, Industry, Civil Society and Government.

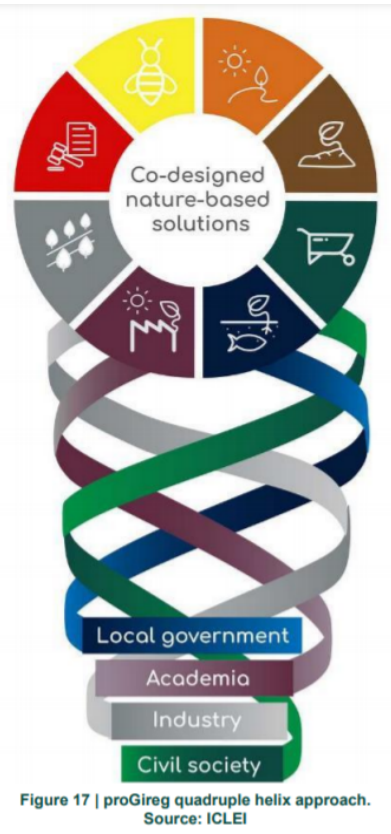

Figure 2. Stakeholder analysis from proGiReg. Source: Deliverable 2.3 on Workshop round 1 in Frontrunner Cities

Without delving into the evaluation of this approach, it is worthwhile to mention that the experts usually fall into the category of Academia. However, each project presents some peculiarities. The ProGIReg claims that the expertise is shared between different stakeholders' categories: Residents and Local Initiatives, Policy makers, local and upper scale institutions, public services and industries. The project therefore acknowledges the relevance of bottom-up initiatives and it distributes the expertise at various levels and in various sectors (ICLEI, 2019.

The UNALAB project defines citizens as users, while attributing the expertise to knowledge institutions (van Dinter and Habibipour, 2019). In another deliverable, it mentions that "local citizens can provide valuable input and ideas, as they may have an interest in NBS or in the area affected by the implementation (Campailla and Titley, 2019: p. 17), while experts are generally considered within "Sectoral Organisations", such as professional organisations/associations and research organisations (Campailla and Titley, 2019: p. 14). Nevertheless, UNALab acknowledges the importance of citizens in the co-design process "Co-design places the involvement of citizens at the very heart of the design of a public 
service... A key principle of co-design is that users, as 'experts' of their own experience, become co-designers (Ståhlbröst et al., 2018: p. 17)

Clevercities reflects on the role of experts, emphasizing their role as separate subjects from Citizens, Authorities and Partners: "The second section "expertise" is characterized by a professional background in implementing and maintenance of green infrastructure in general, such as landscapers/architects, gardeners or handicraft businesses who will be involved in the process of the school garden co-design and implementation." (FHH, 2019: p. 35).

In this case the expert knowledge is needed to deliver the goals of the project providing functional technical and theoretical insights.

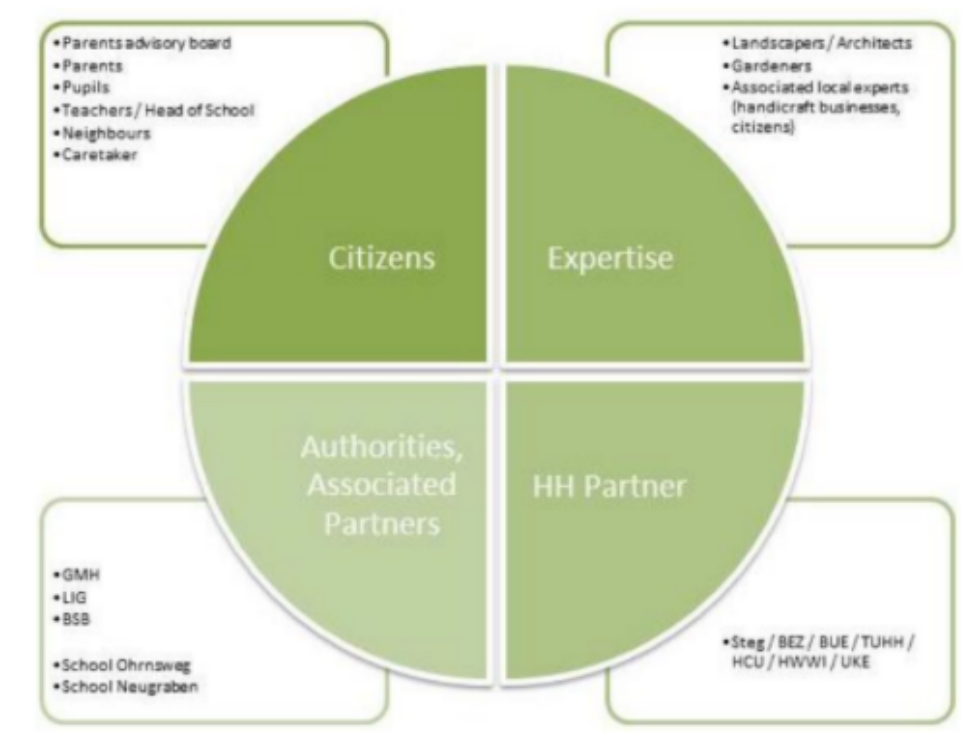

rs' constellation (CLEVER Hamburg team, 2019).

Figure 3. Stakeholder analysis from Clever Cities.

Source: CAL-Specific Co-implementation Plan. Deliverable 2.3

Other projects tend to restrict the category of experts to researchers and universities. Green Surge project refers to "Researchers", as a separate group, separated from Government agencies/public bodies, NGOs and civil society organisations, Planners Developers and private sector business, Community groups and Individuals. Similarly, GrowGreen isolates "University and scientific stakeholders" from Civil Society, Council Departments, Council Technician, Public sector and sector providers.

Looking at the stakeholder analysis carried out in different projects, we noticed that the definition of experts is often taken for granted and not sufficiently problematized. In addition, based on the review of the projects reports and deliverables and on our personal experience in the field, we noticed that the project partners do not have a reflexive attitude on their role as experts who interact with local communities: many stakeholder analyses identify and map local actors, without including the international experts who are actually involved in the project implementation as part of the project consortium. The expertise of the work package leaders clearly defines the conceptual framework whereby the local actors implement the project activities. For this reason, the expertise of the wp leaders has to be in line with the pilot regions' leaders and with the local stakeholders. Considering the differences, in terms of nationalities, languages and stakeholder's categories (e.g., researchers and public 
administrators), the sharing of the expertise may result problematic, affecting the consistency of the project.

\subsection{Governance model and co-creation}

A common feature to all the selected projects is a deep reflection about governance models and arrangements. The NBS projects initially study the literature on green governance and then monitor the direct experience in the pilot cities, including the lessons learned along the project implementation.

Green Surge includes its findings in the publication "Innovative Governance for Urban Green Infrastructure. A guide for practitioners". According to Green Surge (Ambrose-Oji et al., 2017), key principles in the Urban Green Infrastructure governance are:

- The acknowledgment of the right for the public and non-state actors to take part in environmental decision making;

- The inclusion of diverse stakeholders in governance decisions.

- The integration of non-state actors with the formal and codified systems of government in the decision making processes;

- The engagement of non-state actors in governance and active management.

In addition, Green Surge presents the spectrum of government and non-government roles in different governance arrangements (see fig. 4). The government actor can be oriented towards a leading or an enabling role. When the government has a leading role, the non-government actors are involved for information and consultation purposes, while, the more the government is enabling, the more non-government actors are empowered.

All the projects draw attention to the very close correlation between governance models and participation. The involvement and engagement of local communities are considered as a priority in order to achieve a successful implementation of the nature-based solutions. Nature4Cities clearly indicates the added value of participation at three levels: substantive, in terms of effective benefits and improvements in the design and planning of NBS; instrumental, to increase the social acceptance of the project and encourage the citizens' support in maintenance activities; and normative, which concerns the fair procedures and the legitimacy of the planned project (Nature4cities D5.2).

Clearinghouse admits that "the engagement of civil society (i.e., social groups, citizens) in UF-NBS is still relatively low" (source), with a prevalence for top-down approaches with a leading role embedded in municipalities. At the same time, the engagement of civil society and private actors is still relatively low, with the majority of fundings coming from municipal fund."

To overcome these criticalities, most of the EU-funded projects put forward the formulas of co-governance, co-creation strategies and co-design processes. To mention some examples, Green Surge defines co-governance as "Partnerships between citizens or citizen organisations and municipalities with power being shared between those involved" (Ambrose-Oji, et al., 2017: p.16). Connecting Nature refers to co-production as "governance method which can be used by cities and other stakeholders when developing nature-based solutions in cities and for the good of cities" (Holscher et al., 2020, p.4). UNALab intends citizens as important partners in the co-creation of public services and refers to the umbrella concept of co-production as a process of co-decision, co-delivery and co-evaluation (Ståhlbröst et al., 2018). 


\section{FIGURE 2: SPECTRUM OF GOVERNMENT AND NON-GOVERNMENT ROLES IN DIFFERENT GOVERNANCE ARRANGEMENTS²}

\begin{tabular}{|c|c|c|c|c|c|c|}
\hline $\begin{array}{l}\text { Government } \\
\text { actor role }\end{array}$ & Leading & $\leftarrow$ & & $\rightarrow$ & Enabling & $\begin{array}{l}\text { None/ } \\
\text { regulatory }\end{array}$ \\
\hline $\begin{array}{l}\text { Form of Non- } \\
\text { government } \\
\text { actor } \\
\text { participation } \\
\text { in } \\
\text { governance }\end{array}$ & Information & Consultation & Involvement & Partnership & \multicolumn{2}{|c|}{ Empowerment } \\
\hline $\begin{array}{l}\text { Non- } \\
\text { government } \\
\text { actor role }\end{array}$ & \multicolumn{2}{|c|}{$\begin{array}{l}\text { Provide information } \\
\text { and views about UGI } \\
\text { plans and projects as } \\
\text { part of decision making } \\
\text { process }\end{array}$} & $\begin{array}{l}\text { Some } \\
\text { involvement } \\
\text { in planning, } \\
\text { management, } \\
\text { care and } \\
\text { maintenance } \\
\text { of UGI }\end{array}$ & $\begin{array}{l}\text { Shared roles } \\
\text { and } \\
\text { responsibilities } \\
\text { around } \\
\text { planning and } \\
\text { management } \\
\text { of UGI }\end{array}$ & $\begin{array}{l}\text { Leasing or } \\
\text { purchasing } \\
\text { of public } \\
\text { land }\end{array}$ & $\begin{array}{l}\text { Management } \\
\text { agreement, } \\
\text { leasing or } \\
\text { purchase of } \\
\text { private land }\end{array}$ \\
\hline $\begin{array}{l}\text { Governance } \\
\text { model }\end{array}$ & \multicolumn{2}{|c|}{$\begin{array}{l}\text { Government actor led } \\
\text { Consultative } \\
\text { Democratic processes }\end{array}$} & $\begin{array}{l}\text { Co- } \\
\text { management }\end{array}$ & $\begin{array}{l}\text { Co- } \\
\text { governance/ } \\
\text { co-production } \\
\text { Consensus } \\
\text { oriented }\end{array}$ & \multicolumn{2}{|c|}{$\begin{array}{l}\text { Non-government actor led } \\
\text { governance } \\
\text { Self governance }\end{array}$} \\
\hline
\end{tabular}

Fig. 4, Spectrum of government and non-government roles in different governance arrangements p.15. Ambrose-Oji, B., Buijs, A., Gerőházi, E., Mattijssen, T., Száraz,L., Van der Jagt, A., Hansen,R., Rall, E., Andersson, E, Kronenberg, J., and Rolf, W. 2017, Innovative Governance for Urban Green Infrastructure: A Guide for Practitioners, GREEN SURGE project Deliverable 6.3, University of Copenhagen, Copenhagen.

Regarding co-creation, CleverCities dedicates specific attention to this concept and provides a guidance on co-creation of Nature-Based Solutions in the deliverables published. Co-creation is defined as "a collaborative approach to engagement which allows stakeholders to collectively design and build more inclusive and sustainable mechanisms for change" (Morello and Mahmoud, 2018: p.93). The co-creation pathway designed by CleverCities is considered a form of open innovation and as a whole process of participation, collaboration and interaction. In this sense, citizens are clearly recognised as key subjects and main producers of knowledge, while the experts involved in the Pilot Cities are mostly identified with

the role of facilitators. Although recognising that "engagement never happens in a neutral context and whenever citizens are invited to participate in any process, there will always be consequences for the distribution of control and power" (Davies, Simon, Patrick, \& Norman, 2012, p. 9), the tension between citizens and experts in the production of local knowledge does not seem analysed or addressed within CleverCities.

To resume, all considered EU-funded projects clearly point out the problem of involving local communities in the co-design of Nature-Based Solutions. The risks of involving citizens as purely "recipients" (Green Surge) is high and it might lead to serious problems of acceptability of the solutions proposed. Nevertheless, two critical aspects would deserve further investigation and reflection. Firstly, whether co-governance effectively means sharing power between the actors involved, as the general formula and structure of Horizon 2020 projects might not always facilitate this sharing of power. Following the work done by Sullivan et al. (2020), it emerged how local communities are consulted, but they cannot be 
considered true co-designers because the projects proposed pre-defined solutions or fail to identify local problems. Secondly, the dynamics between experts, local communities and local authorities does not seem to be sufficiently explored or covered in the project deliverables. This tension between local authorities, local communities and experts could become even more evident taking into account that not all groups are identical and that it is likely to be more difficult to reach and engage vulnerable groups.

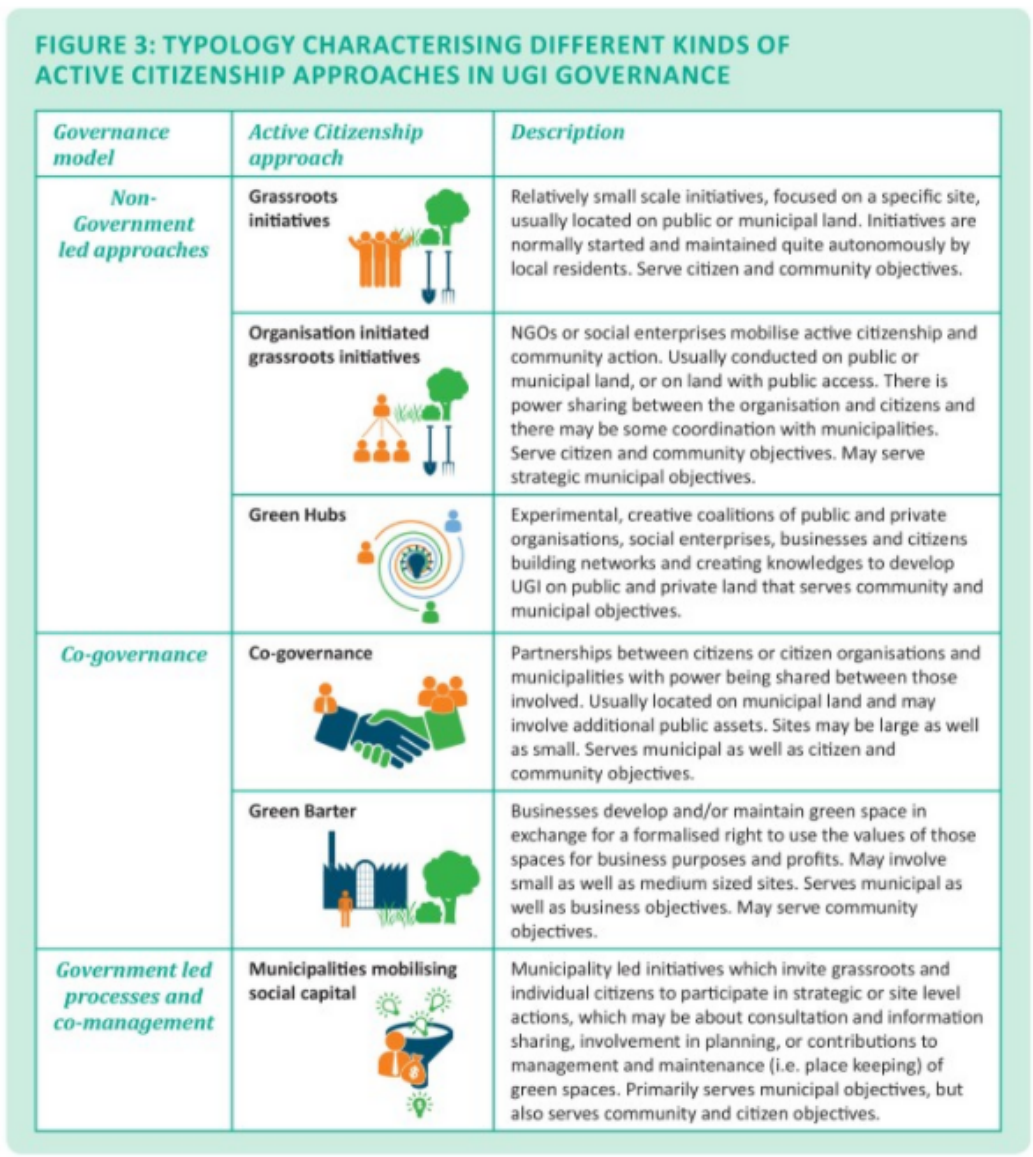

Fig. 5, Spectrum of active citizens approach in UGI Governance, p.16. Ambrose-Oji, B., Buijs, A., et al., Innovative Governance for Urban Green Infrastructure: A Guide for Practitioners, GREEN SURGE project Deliverable 6.3, University of Copenhagen, Copenhagen.

\subsection{Living Labs and participatory processes}

A central element of the NBS projects is the implementation of "Living Labs". The name can differ from project to project, as well as some features and functions. However, they are generally intended to answer to the common need of establishing and formalizing public participation within cities. Bulkeley et. Al. (2018) describe their role in the following way: "They thus act as a bridge or interface between policies and scientific work to inform urban planning measures, governance and techniques (Bulkeley et al.,2018)."

Green Surge uses the term Green Hubs and Urban Living Labs, defining them as "innovative coalitions between citizens, businesses, and non-governmental organisations. Green Hubs often play a brokerage role in the exchange of resources such as knowledge, creativity and money."(Ambrose-Oji, et al., 2017: p.19). Clever Cities defines CLEVER Action Labs as "Urban Living Labs (ULL) that ideally are strategic, civic 
and organic, and incorporate a wide spectrum of experimental platforms for governance, interventions and change. CALs are test-beds where cities implement innovative co-creation processes and nature-based solutions, bringing together different socio-spatial relations" (Morello and Mahmoud, 2018: p.108). Phusicos has developed Living Labs, based on the definition of Leminen (2013): A Living Lab is a physical region and interaction space, in which stakeholders form a quadruple helix innovation network of companies, public agencies, universities, users, and other stakeholders in the pursue of collaborating for the creation, prototyping, validating, and testing of new technologies, services, products, and systems in real-life contexts. (Fohlmeister et al., 2018: p. 4)

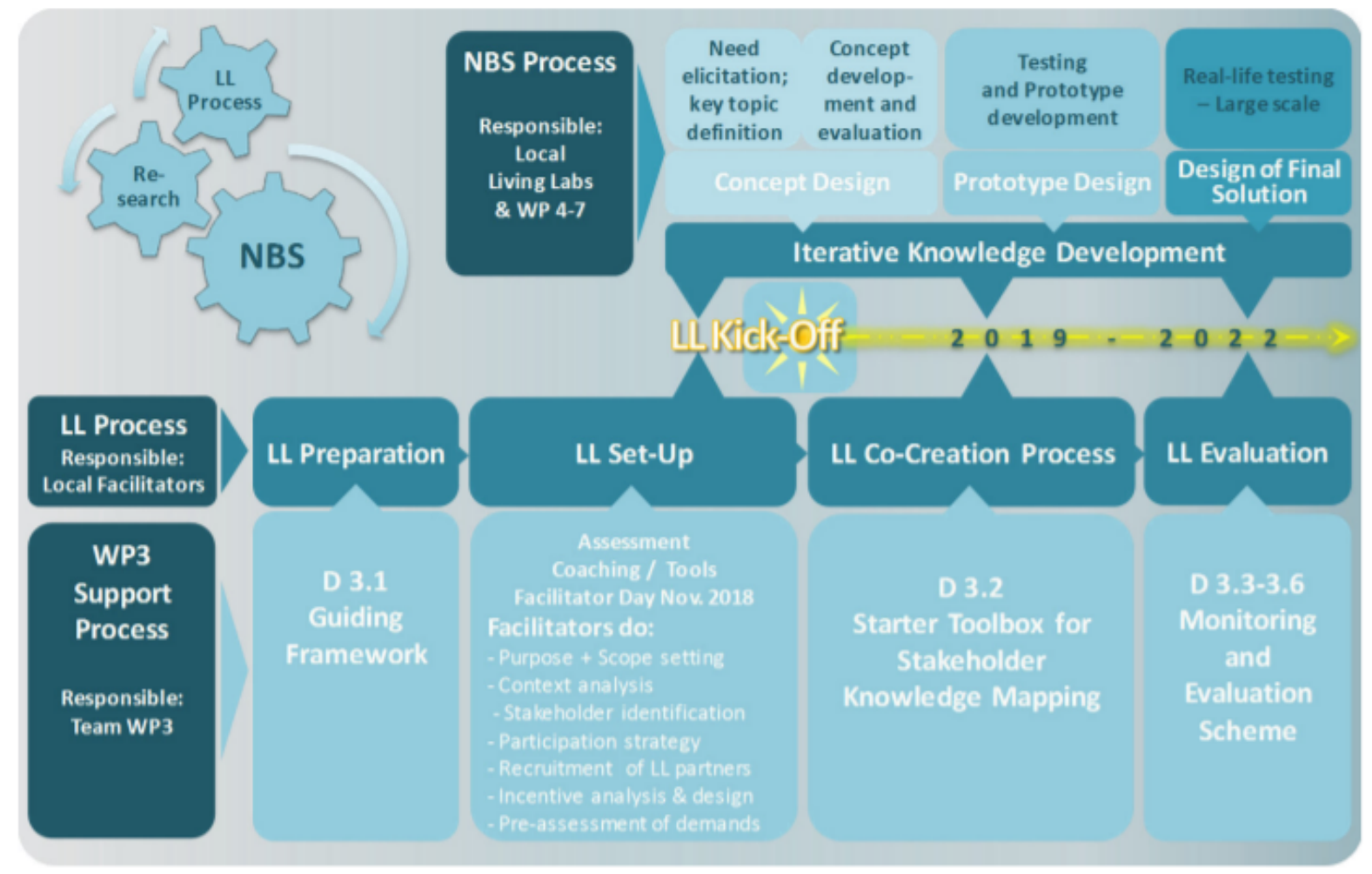

Fig. 6,Overview of the PHUSICOS Living Lab process in its contextual embedding of NBS development, p.57. Fohlmeister et al., 2018.

The project UNaLAb deserves a particular mention for the level of detail in presenting and describing the "Urban Living Labs" (ULL), both in terms of functioning and roles involved. Implemented in the frontrunner cities, the ULLS operate as dedicated spaces for experimentation in a real-life urban setting (Habibipour et al., 2020). In presenting the seven key components of the Living Labs, the project defines partner and users involved (based on the quadruple-helix approach), and indicates their possible role that they can play: passive role, experimenter, innovator, lead participant, tester (Habibipour et al., 2020).

More into details, UNaLAB clearly defines a series of roles for the functioning of the ULLs, both internal and external. Internal roles include ULL manager, Human interaction specialist, Pilot Manager, Panel Manager and Project Manager; while external roles include Innovator, Users, Affectees, Problem owners, Finances and Context providers. The substantial difference between the two categories is that the internal roles are relevant for setting-up the ULL, while the external roles manage the ongoing activities in the Lab (Habibipour et al., 2020). 


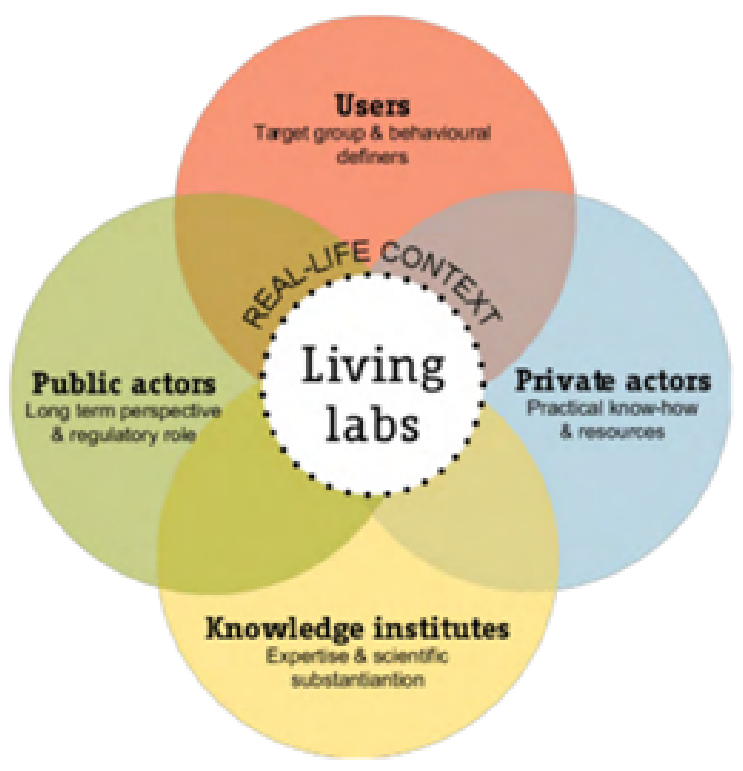

Figure 7: Urban living labs: a living lab way of working. Steen and Van Bueren (2017)

In this context, UNaLAB clearly acknowledges and gives value to the involvement of local communities, and the ultimately goal of the ULLs is to foster collaboration and co-creation among all the different stakeholder groups involved in the project. It also clearly defines the scale with the possible different levels of citizens engagement: no engagement, symbolic engagement, engagement by advise, engagement by weak control, engagement by doing, engagement by strong control (Habibipour et al., 2020). Moreover, UNaLAB explicitly mentions the engagement of experts as a requirement, in the role of moderators: "engage skilled professionals with high level of expertise in the team to take care of the situation and moderate the engagement process (Habibipour et al., 2020).

Despite many EU-projects effectively define methods, tools, principles, lessons learned for stakeholder engagement, co-creation and other activities within the Living Labs, the dynamics and the tensions between international experts and local communities are rarely emphasized or discussed in public documents and deliverables. The relevance of this topic is important, especially if we think about the innovative models for urban governance that have been developed in the field of NBS. As highlighted by Nature4Cities, "currently, there is a tendency to shift governance responsibilities towards economic agents (the market) and civil society agents (the community)." (Nature4Cities, 2016: p.22).

One attempt was made by Green Surge, describing the dynamics of distilling the key areas of interest of each Urban Living Lab. Following the graphic indicated in Figure 8, participatory workshops within the ULLs are seen as "demand of knowledge", while external research is indicated as "knowledge provider". Therefore, the ULL is seen as a place of "synthesis" among the key areas of interest, with professionals or experts acting in the role of coordinators. 


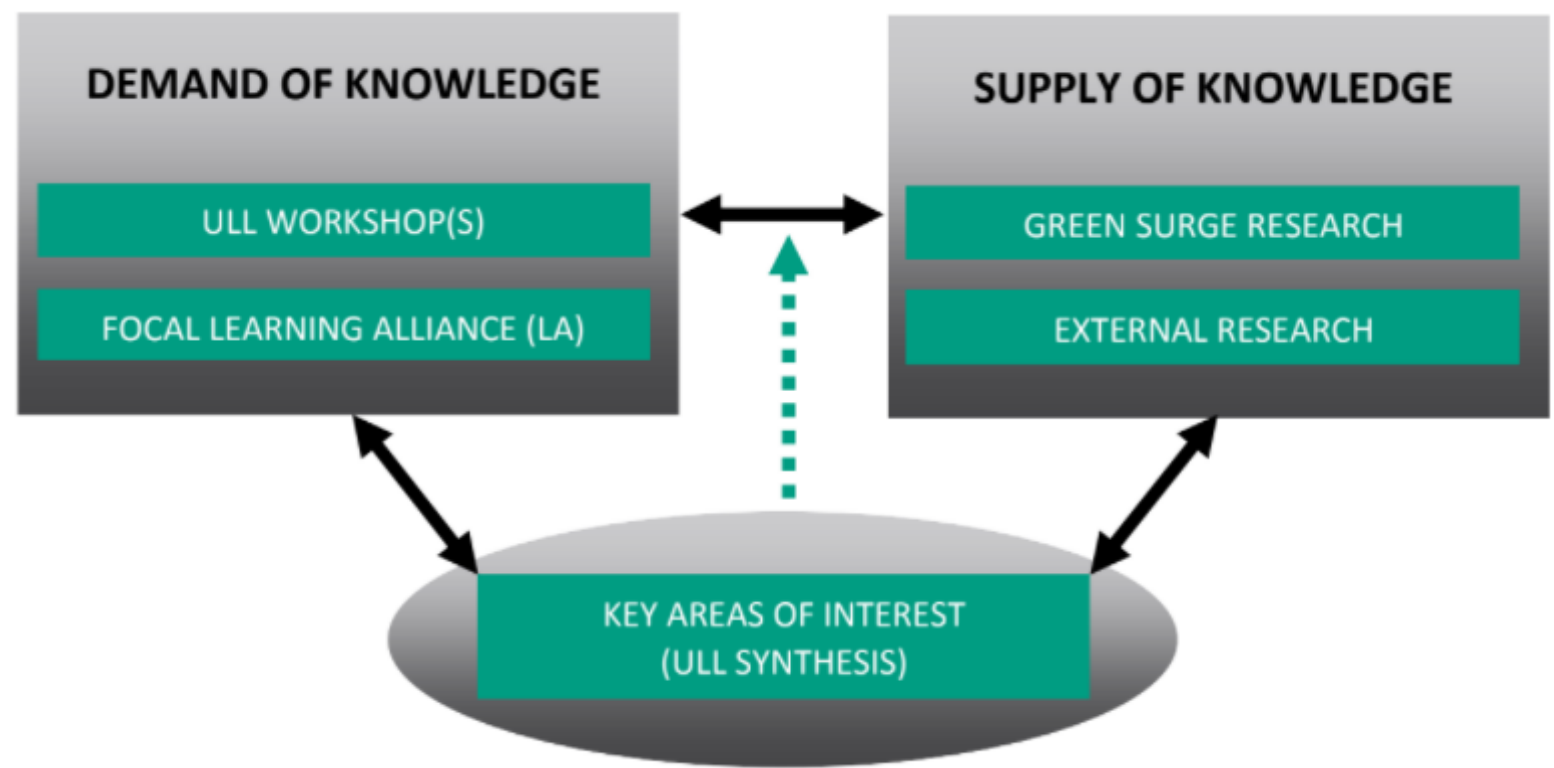

Fig.8: Diagram showing the dynamic and continuous process of distilling the key areas of interest of each ULL by the ULL Coordinator. Van der Jagt et al. 2016

The research on the Living Labs does not only look at their overall structure and definition, but includes reviewing available reports of co-creation and co-design workshops. These participatory activities usually are at the core of the functioning of Living Labs. The organisation and the structure of these workshops can vary from project to project, and the outcomes of these participatory processes are usually well documented in public project deliverables. The outcomes of these activities are sometimes supported by final reflections, lessons learned or unsolved challenges. Considering the scope of this research, the paper highlights only some of the most interesting findings related to the dynamic experts-local communities.

UNaLAb points out the importance for local communities to gain familiarity with both co-creation and Nature-based Solutions at the early stage of the project (van Dinter and Habibipour, 2019). In the same direction, proGireg highlights a tension between project partners and local communities, which affect their level of participation. Given that the intrinsic nature of co-designing NBS requires to keep options open, some citizens might feel disappointed or disengaged in case of lack of clarity and certainties; on the other hand, involving citizens too late in the process would break the core principle of co-design, which is early engagement (Hanania and Wilk, 2020). Green Surge witnessed difficulties in engaging stakeholders in the Labs, especially in those local contexts where they are not used or where the tradition is low (van der Jackt et al., 2016). CLEVER Cities suggests to overcome the challenges of knowledge gaps and the need of integrating local stakeholder and experts by using the existing knowledge and promoting successful pioneer projects (Schmalzbauer 2018).

\section{Conclusions}

The research has explored the role and involvement of experts in the governance of EU-funded projects on Nature-based Solutions. Evidence collected by literature review of project deliverables and open access publication shows how the matter of involving local communities in the project implementation is a common and sincere concern among all the considered EU projects. However, the research underlined some problematic issues. 
First, most of the considered projects lack reflexivity about the role and involvement of experts, especially when it comes to establishing the dynamics between international advisors partners and local communities. Classic stakeholder analyses make efforts in identifying local expertise, but the involvement of consortium partners and international experts seems taken for granted. The communication between work package leaders and the representatives of pilot cities enhances a better consistency of the project activities, in terms of shared knowledge and objectives. Moreover, this theme is of pivotal importance for the legacy of the projects, as a common shared knowledge empowers local communities. The communication between the partners and the international consortium is very demanding in terms of time and resources, and is often overlooked because it is not part of the project activities and deliveries and can be the cause of divergences and conflicts. For these reasons these issues about communication should be discussed and problematised from the first steps of the projects.

Secondly, although most of the considered projects show awareness about different levels of engagement of local communities, this does not mean that a full engagement and participation of local communities is achieved. Enlarging the scope, a reflection about the same structure of the Horizon 2020 programme seems useful: as emerged in the research from Sullivan et al. (2020), the funding system is based on a bid, forcing to define precisely beforehand what is going to be implemented in a project. This structure often leads international experts and partners to define solutions up-front, without deep consultations with local communities, raising issues of legitimacy and with the risk of making the involvement of local communities superficial and not essential.

By looking at the governance models identified and the work carried on in many Living Labs, efforts have been made to make the participation of local communities more effective, especially through the methodology of co-creation workshops and co-design activities within the Living Labs. In this approach, citizens are recognized as producers of local knowledge (which need to be integrated into the project implementation), while experts tend to be seen as facilitators and coordinators of co-creation activities. These considerations can lead to the broad discussion about the importance of recognizing the value of citizen and stakeholder involvement, and the role of planners and urban experts within society.

How to merge international expertise and local knowledge might appear in the procedural and methodological descriptions of how to run co-creation activities, presented by some projects in ad-hoc toolboxes, toolkits or handbooks. Nevertheless, this paper argues that more research and consideration would be needed in order to truly understand the dynamics and the tensions between local knowledge and international expertise in the field of Nature-based Solutions. As mentioned by CleverCities: "Stakeholder engagement matters for a number of reasons. Well planned engagement with those who will be affected by the 'solutions' developed and/ or those who have influence over if and how solutions can be co-implemented, will be crucial in helping you to reach the best possible outcome. An inclusive group of stakeholders will bring a breadth and depth of knowledge, skills and resources which are unlikely to be found through traditional 'expert' groups. A truly participatory approach to stakeholder engagement will also encourage the development of new relationships which in turn can lead to more innovative ways of working, creative solutions and, potentially deeper systems-level change, e.g. changes in organisational culture, policies and procedures." (Morello and Mahmoud, 2018 ).

Future research might focus on how to effectively mix international expertise and local knowledge, how to balance the provision of international advisory and the understanding of the local context, and how to manage and address the distribution of power and control among stakeholders involved in co-creation processes.

Lastly, one challenge seems to remain unaddressed and represents an important goal to incorporate in the next programmes of funded projects. Ensuring the long-term maintenance and monitoring beyond 
the end of the projects (the funding period) is a critical point, difficult to capture in the very short term. This is why most of the projects define KPIs and guidelines, but few measurements or assessments within the project deliverables. This topic is closely related to the "legacy" of EU-funded projects within the local context in terms of capacity-building and ownership of both local authorities and local communities, well beyond the actions implemented on-site.

\section{References}

Ambrose-Oji, B., Buijs, A., Gerőházi, E., et al., 2017. Innovative Governance for Urban Green Infrastructure: A Guide for Practitioners, GREEN SURGE project Deliverable 6.3, University of Copenhagen, Copenhagen. [online] Available at: https://www.e-pages.dk/ku/1337/html5/ (Accessed September 2021)

Campailla, S., Tiley, R., 2019. STakeholders and target groups. Deliverable D7.1. UNALab. [online] Available at: https://unalab.eu/system/files/2020-02/d71-stakeholders-and-target-groups-report-2020-02-17.pdf (Accessed: July 2021)

Caselli, D. (2020) Esperti. Come studiarli e perché. Bologna: Il Mulino

European Commission (2021). Evaluating the impact of Nature-Based-Solutions: A Handbook for Practitioners [online] Available at:

https://op.europa.eu/en/publication-detail/-/publication/d7d496b5-ad4e-11eb-9767-01aa75ed71a1

(Accessed: June 2021)

European Commission (2020). Nature-Based Solutions: State of Art in the EU-funded projects. [online] Available at:

https://ec.europa.eu/info/publications/nature-based-solutions-state-art-eu-funded-projects_en

(Accessed: June 2021)

Fohlmeister, S., Zingraff-Hamed, A. et al., 2018. Guiding Framework for Tailored Living Lab Establishment at Concept and Demonstrator Case Study Sites. Phusicos. [online] Available at:

https://phusicos.eu/wp-content/uploads/2018/10/D3 1 GF Final Version complete 201807312-Disclai mers.pdf (Accessed September 2021)

Funtowicz, S., \& Ravetz, J. (1993). Science for a post-normal age. Futures, 25(September), 739-755.

Habibipour, A., Ståhlbröst, A., et al., 2020. Living Lab Handbook for Urban Living Labs developing Nature-Based Solutions. UNALab. [online] Available at:

https://unalab.eu/en/documents/urban-living-lab-handbook (Accessed September 2021)

Hanania, S., Wilk, B., 2020. Co-designing Nature-based Solutions in Living Labs. Deliverable D2.5: Final report on co-design workshops in Frontrunner Cities (Dortmund, Turin, and Zagreb). proGIreg. [online] Available at:

https://progireg.eu/fileadmin/user_upload/Deliverables/D2.5_Report_on_final_WS_round_in_FRC_proGI reg_ICLEI_2020-01-31.pdf (accessed: September 2021)

Hölscher, K., Frantzeskaki, N., Lodder, M., et al. 2020. Co-Production Guidebook. [online] Available at: https://connectingnature.eu/innovations/co-production (Accessed: September 2021)

ICLEI, 2019. Co-designing Nature-Based Solutions in Living Labs Deliverable 2.4 on Workshop round 2 in Frontrunner Cities (Dortmund, Turin, and Zagreb). proGireg [online] available at: https://progireg.eu/fileadmin/user_upload/Deliverables/D2.4_Report_on_WS_round_2_in_FRC_proGIre g_ICLEI_2019-10-01.pdf (Accessed: September 2021) 
ICLEI, 2019. Co-designing Nature-Based Solutions in Living Labs Deliverable 2.4 on Workshop round 2 in Frontrunner Cities (Dortmund, Turin, and Zagreb). proGireg [online] available at: https://progireg.eu/fileadmin/user_upload/Deliverables/D2.4_Report_on_WS_round_2_in_FRC_proGIre g_ICLEI_2019-10-01.pdf (Accessed: September 2021)

ICLEI, 2019. Co-designing Nature-based Solutions in Living Labs Deliverable D2.5: Final report on co-design workshops in Frontrunner Cities (Dortmund, Turin, and Zagreb). proGireg [online] Available at: https://cordis.europa.eu/project/id/776528/results (Accessed: September 2021)

ICLEI, 2019. Methodology on spatial analysis in front-runner and follower cities Deliverable 2.1. proGireg [online] available at: https://cordis.europa.eu/project/id/776528/results (Accessed: September 2021)

Konjaria-Christian, S., Pastoors, J., et. al. 2019. CAL specific co-implementation plan. Clever Cities [online] Available at: https://cordis.europa.eu/project/id/776604/results/de (Accessed: September 2021).

Jasanoff, S. [edited by] (2004). States of knowledge. The Co-production of Science and the Social Order. New York: Routledge

Nature4Cities, 2016. D5.2 Citizen and Stakeholder Engagement strategies and tools for NBS Implementation. [online] Available at: https://www.nature4cities.eu/results (Accessed: September 2021)

O'Sullivan, F., Mell, I., and Clement, S. (2020) Novel Solutions or Rebranded Approach: Evaluating the use of Nature-Based Solutions in Europe. In Frontiers of Sustainable Cities, Volume 2. [online] Available at: https://www.frontiersin.org/articles/10.3389/frsc.2020.572527/full (Accessed: July 2021)

Morello, E., Mahmoud, I., 2018. CLEVER Cities Guidance on co-creating nature-based solutions. Deliverable 1.1.5. CLEVER Cities. [online] Available at:

https://clevercities.eu/resources/deliverables-and-reports/ (Accessed: September 2021)

Schmalzbauer, A.., 2018. Guiding Framework for CLEVER Cities Activities. Deliverable 1.1. [online] Available at:

https://clevercities.eu/fileadmin/user_upload/Resources/D1.1_Theme_1_Barriers success factors_co-cr eation HWWI 12.2018.pdf (accessed September 2021).

Ståhlbröst, A., Habibipour, A., Chronéer, D., et al., 2018. UNALAb ULL Framework. D2.1 Deliverable. UNALab. [online] Available at: https://unalab.eu/en/documents/d21-unalab-ull-framework (Accessed September 2021)

Steen, K., \& Van Bueren, E. (2017). Urban Living Labs: A Living Lab way of working. Amsterdam Institute for Advanced Metropolitan Solutions, Delft University of Technology: Delft, The Netherlands.

van der Jackt, A., Botzat, A., et al., 2016. Iterative Place-based knowledge gathering in Urban Learning Labs. GREEN SURGE. [online] Available at:

https://ign.ku.dk/english/green-surge/rapporter/D7 2 Iterative Place-based Knowledge Gathering.pdf (Accessed: September 2021)

van Dinter, M., Habibipour, A., 2019. Co-creation Workshops Report D2.2. UNALab. [online] Available at: https://unalab.eu/system/files/2020-02/d22-co-creation-workshop-report2020-02-17.pdf (Accessed: July 2021) 